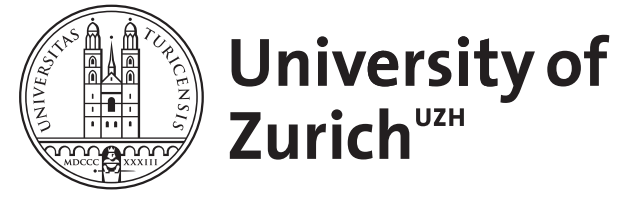

\title{
Scott Weems : Ha! The Science of When We Laugh and Why
}

Platt, Tracey ; Ruch, Willibald

DOI: https://doi.org/10.1515/humor-2015-0101

Posted at the Zurich Open Repository and Archive, University of Zurich ZORA URL: https://doi.org/10.5167/uzh-171932

Journal Article

Published Version

Originally published at:

Platt, Tracey; Ruch, Willibald (2015). Scott Weems : Ha! The Science of When We Laugh and Why. HUMOR: International Journal of Humor Research, 28(4):657-662.

DOI: https://doi.org/10.1515/humor-2015-0101 


\section{Book Review}

Scott Weems. 2014. Ha! The Science of When We Laugh and Why. New York: Basic Books. 230 pp. ISBN 978-0-465-03170-2. USD 26.99. EUR 19.60

Reviewed by Tracey Platt, Department of Psychology, University of Zurich, Binzmuehlestrasse 14/7, Zurich CH 8050, Switzerland, E-mail: tracey.platt@psychologie.uzh.ch

Willibald Ruch, Department of Psychology, University of Zurich, Binzmuehlestrasse 14/7, Zurich CH 8050, Switzerland, E-mail: w.ruch@psychologie.uzh.ch

DOI 10.1515/humor-2015-0101

The value of a scholarly journal such as HUMOR reviewing a book intended for a general audience and written by someone without a research record in humor and laughter is to provide reliable guidance on the quality of the book, the author's standing and what experts in the field think of it. As the author states, "Ha! is about an idea" (p. xiv). But since Scott Weems' background is the empirical discipline of cognitive neuroscience, what we are offered is a look at humor and laughter through the eyes of someone with expertise in issues such as the training of working memory. What, then, is the book about exactly?

Weems sets out on a quest to use the science underlying humor and laughter to uncover what is happening in "the brain" (p. xii) and to figure out what we really find funny and why. The book is in three parts with a conclusion, acknowledgments, notes, and an index. Unfortunately, there is no traditional referencing, which hampers the reader in disentangling statement from conjecture.

Part One focuses on the question, "what is humor?" The first chapter, "Cocaine, Chocolate, and Mr. Bean," lays out the arguments for when and why we laugh through three laughter case studies. The first study explains the Tanganyika Laughter Epidemic, showing how an epidemic of laughter, which initially affected school students, escalated over four months. The second example explores the joke, Stop-over at the Empire State Building, a failed joke-attempt relating to the World Trade Center attack in New York, which was told by Gilbert Gottfried at a stage roasting of Hugh Hefner. The final case study details the response by the author's wife to a scene in the film, Titanic (1997). Weems then explicates the link between these examples and humor, suggesting that the reader should look at humor not in terms of the jokes but as a psychological coping mechanism. He then tries to define what humor is, linking it to mirth and to the so-called funniest joke in the world, suggesting that "humor should be considered a process, not an outlook or behavior" as it results from "a battle in our brains between feelings and thoughts" - "a battle that can only be understood by recognizing what brought the conflict on" (p. 9). 
Chapter Two, "The Kick of the Discovery,” explores what happens in the brain when "insight" occurs; this is the name given to finding the solution to a difficult problem, an important activity for humor. Utilizing his cognitive neuroscientific background, Weems explains the three stages (constructing, reckoning, and resolving) of how the brain turns conflict into reward, with reward coming from the feelings of pleasure experienced on achieving "insight." The link is then made to the General Theory of Verbal Humor and the manipulation of scripts which have to be resolved. Samson and Hempelmann's (2011) research is used to show how background incongruity increases the funniness of a joke. This, Weems argues, is evidence for the "resolving" part of his three stages. He claims that some naturally occurring humor, such as humorous newspaper headings, may mix up the three stages and demand a simultaneous constructing, reckoning and resolving of conflicting interpretations (p. 48). The chapter concludes by explaining the difference between those with either a liberal or a conservative point of view and how in brain studies of liberals, the anterior cingulate (the conflict resolution part of the brain) proved larger than for conservatives, who in turn had larger amygdala than the liberals. Anterior cingulate activity is also linked to religious intensity, with a decrease in activity occurring when religious people think about God. To relate all of this to humor, Weems concludes that these brain differences assist in dealing with confusion, and that without confusion, "we would never laugh" (p. 50). Based on these anatomical findings, he states that conservatives are probably more emotional, tending to resolve complexities through their feelings. There are indeed data on the humor preferences of conservatives showing that conservatism is a predictor of liking incongruity-resolution humor, which is typically considered less complex than other forms. But this chapter does not add to existing findings.

Chapter Three, "Stop Over at the Empire State Building," returns to Gottfried's joke, which he described in Chapter One as getting him booed for telling it too soon after the events of 9/11. The comedian only recovered by telling the ultimate dirty joke, The Aristocrats, which got the audience back onside and brought down the house with laughter. However, here we are told that it is The Aristocrats joke that elicited the booing (cf. p. 2, p. 54). In Chapter One, Weems stated, "there is no way you'll ever see it in print, just as you won't see it in recordings of the roast. The joke's depravity either broke the cameras or scared Comedy Central so much it burned the tape shortly thereafter" (p. 6). Thus it seems there is no way to resolve these two conflicting accounts. Thankfully, however, YouTube remained unaffected by such sensibilities, and from this source your reviewers can assure all those anxious not to waste precious time on this mystery that the audience does actually laugh at The Aristocrats joke and not vice versa. 
The first of three sections comprising the rest of Chapter Three is dedicated to explaining the "bad rap" that humor has historically received. Ranging from laughter being perceived as a distractor from serious matters in Plato's republic to Hobbes' belief that humor was for those of inferior intellect, we are even told how often God laughs at rather than laughs with people, as recounted in the Bible, and that the laughter of Jesus was never documented. The reason for all this negativity is apparently the subversive nature of humor. Such a framing of history allows the author to argue that the mechanism of humor even in "sick or cruel" jokes acts to elicit an emotional conflict that will create laughter. The next section, "Scary Movies and Relief," pursues this theme of emotional complexity to illustrate why we laugh when released from threat or discomfort. A concluding section on "Jokes with a Target" discusses the Von Economo neurons in connection with the anterior cingulate (p. 68). It seems these spindle cells are found in relatively few species other than humans and are responsible for social awareness and emotion control. Their existence is linked to the idea that conflict is needed for the production of humor and laughter - in this case, emotional and personal conflict. This is why, Weems argues, we find so many jokes targeted at others.

The book's second part tries to define humor and who we are. Chapter Four, "Specialization Is for Insects," asks what purpose humor serves, explaining that a human brain is not a specialist brain but more generalist, as can be seen in many types of pathological laughter, such as epileptic laughter. One consequence of having a generalist and unpredictable brain is the existence of individual differences, especially in humor. A section on states and traits reports on various research agendas, such as the quantitative formula of humor proposed by Peter Derks (p. 85). Weems assures us that this formula is actually "onto something" - surely a relief to the (now emeritus) professor of psychology who has worked on humor for over twenty years. After an irrelevant page-long diversion on Hans-Jürgen Eysenck, his helpful wife Sybil, and their personality assessment tool the Eysenck Personality Questionnaire, this chapter continues with an account of the work of Paul Pearson. This demonstrates that cartoonists are high in psychoticism (the personality trait, not, we are reassured, the pathology). But the author (perhaps like his readers) must have become a little lost when he speaks about "the cartoonists in Eysenck's study" (p. 88). It is of course Paul Pearson's study, which Weems claims is important and influential (p. 87).

The chapter concludes by highlighting the problem that numerous (and here unreported) scientific studies have shown that creative people are high in psychoticism and neuroticism. Nevertheless, Weems claims that one cannot generalize from these because they "measure different things" like "professional 
artists; others students; still others a mixture of both" (p. 88). This is simply nonsense, since having a wide selection of participants (all humans as the common denominator) should be the best way to generalize confidently: these samples are heterogeneous enough to capture all the nuances of people's personalities - so long as all of them were measured using the same personality scale. Is this in fact what the author meant to say? One of the author's reviewers is named as the "German" (actually Austrian) researcher whose comprehensive study on personality and humor "didn't just give one or two personality tests, he gave twelve” (p. 89). Weems proceeds to report these findings by Ruch.

Based on these studies, we are reassured once again by Weems that he does not mean that comedians are mentally unbalanced and schizophrenic (although no-one has said that they were), rather that the findings relate to his idea that cultivating conflict generally creates more humor. This he links to a person's ability to produce and appreciate humor. Interestingly, he also relates it to sensation-seeking individuals (p. 90) and how "we" (cognitive neuroscientists, presumably) can see how sensation-seekers respond to humor by observing their brain processes.

The next section is "The Fairer Sex", which begins by explaining how “women can't tell jokes ... and don't get jokes” (p. 92) and continues over seven pages to explain why this assumption is wrong. Although it is not referenced, most of Weems' explanation is covered by the 1990 work on "The Ritualisation of Laughter" by Grammer and Eibl-Eibesfeldt. Once again, the book contributes little new, other than a platform for the Weems' personal anecdotes. The closing section explains the chapter's title, "Specialization Is for Insects," covering the flexibility of our brains and how the appreciation of laugher changes from childhood. Surprising omissions here are the work of Sroufe and Waters (1977) and of Rothbart (1981), who investigated the cognitive elements of infant humor and what is required to generate laughter. Rothbart proposed the arousal/safety model of laughter, which explains Weems' "peekaboo" example quite satisfactorily.

"Our Computer Overlords" is the sci-fi title of Chapter Five. This is again predominantly anecdotal, but sandwiched between is a useful component. Here, information given does actually elucidate the scientific endeavor of computational humor and the lack of creativity that hampers a computer in comprehending humor. Although the rationale is never made clear as to how this topic fits into the section's "what for" question, one can only hope it is to show that we humans, thankfully, do laugh because we are not computers.

The third and final part of the book aims at discussing "so what?" The chapter titled "The Bill Cosby Effect” opens with Norman Cousin's account of his 1970 s recovery due to his laughter treatment. Weems reports, "[i]n fact, he 
laughed himself out of an illness” (p. 134), but Cousins himself never claimed his recovery was due to laughter alone.

One problem throughout the book is that Weems speaks loosely of "humor", often using it interchangeably with "laughter." Another concerns his frequent use of speculation and personal anecdote: "as soon as Voss began his act, I could tell Laura [Weems' wife] was not impressed.” (p. 152). How could he tell? Did he give her a twenty-item questionnaire on a ten-point Likert scale to assess her mood or state? Or a funniness rating scale? Unfortunately, it seems not. So, like much else, the argument for connectedness to the joke teller must remain speculative, despite the fact that the section concludes by explaining rule violations and the role of social presence in making things more humorous.

It was difficult for the reviewers to continue a serious critical assessment of this error-prone book after reading (p. 146) that "the idea of humor styles was developed by Willibald Ruch...[and] assessed using a test called the humor styles questionnaire”. The real authors of the pioneering HSQ are Martin et al. (2003) who should have been given their due honor. Earlier still, it was Ken Craik and his Berkeley colleagues who first talked about humor styles.

Overall, Weems' attempt to relate core findings from humor research to possible neurological underpinnings can be applauded: the two domains will grow predictably closer in the future. Maybe the task is simply too difficult right now, since there are too few neuroscience studies of humor to report. It may also be that the behavioral side is not yet entirely understood so that nowhere can concepts easily be matched. While however the goal of $\mathrm{Ha}$ ! is worthwhile, the book itself is not a worthwhile addition to a scholarly reader's library, given the ratio of "noise" to solid information. Nor is it an accurate account of the field of humor research. Weems says, "[m]y goal in this book is to act as a translator, perhaps mediator too, pulling out interesting findings from each of these fields. And by combining their insights, forming a new field altogether - Humorology" (p. xvii). It might be advisable, before setting oneself up as a humor tour guide for this complex area, to study the topics in some depth, and to cite more accurately those who have done the work. Otherwise, researchers who have chosen to dedicate their careers to doing precisely that may feel belittled for preferring scientific specialization to anecdote, like the insects in Weems's chapter two.

\section{References}

Grammer, K. \& I. Eibl-Eibesfeldt. 1990. The ritualisation of laughter. In Walter A. Koch (ed.), Natürlichkeit der Sprache und der Kultur: Acta Colloquii, 192-214. Bochum: Brockmeyer. 
Martin, R. A., P. Puhlik-Doris, G. Larsen, J. Gray \& K. Weir. 2003. Individual differences in uses of humor and their relation to psychological well-being: Development of the Humor Styles Questionnaire. Journal of Research in Personality 37. 48-75.

Rothbart, M. K. 1981. Measurement of temperament in infancy. Child Development 52. 569-578.

Samson, A. C. \& C. F. Hempelmann. 2011. Humor with backgrounded incongruity: Does more required suspension of disbelief affect humor perception? Humor-International Journal of Humor Research 24(2). 167-185.

Sroufe, L. A. \& E. Waters. 1977. Attachment as an organizational construct. Child Development 48. 1184-1199. 